\title{
Clinical and echocardiographic outcomes after repair of mitral valve bileaflet prolapse due to myxomatous disease
}

\author{
Vincent Chan, MD, MPH, ${ }^{\mathrm{a}}$ Marc Ruel, MD, MPH, ${ }^{\mathrm{a}, \mathrm{b}}$ Sophia Chaudry, MD, ${ }^{\mathrm{a}}$ Stephane Lambert, MD, ${ }^{\mathrm{a}}$ and \\ Thierry G. Mesana, MD, $\mathrm{PhD}^{\mathrm{a}}$
}

\begin{abstract}
Objective: Repair of mitral regurgitation (MR) due to bileaflet prolapse poses many technical challenges. The late outcomes after repair are also not well characterized in this population. Published series have often included patients with mixed causes of prolapse and/or lack long-term echocardiographic follow-up. Myxomatous disease represents an important cause of bileaflet prolapse and MR and, thus, served as the focus of the present study.
\end{abstract}

\begin{abstract}
Methods: A total of 142 patients, mean age $60.4 \pm 13.2$ years, underwent mitral valve (MV) repair of bileaflet prolapse due to myxomatous disease from 2001 to 2010 . Concomitant coronary artery bypass grafting was performed in 16 patients (11\%). All patients were followed up by a dedicated MV clinic with a follow-up interval that extended up to 8.6 years.

Results: No hospital deaths occurred. Ring annuloplasty was used for all patients. Additional MV repair techniques included chordal transfer in 73 , a hybrid-flip-over technique in 23 , polytetrafluoroethylene neochords in 26, edge-to-edge repair in 11, and commissuroplasty in 9. Prolapse involving more than 1 posterior leaflet scallop was observed in 103 patients $(73 \%)$, and prolapse of more than 1 anterior leaflet scallop was observed in 76 $(54 \%)$. During follow-up, 4 patients had MR grade $2+$ or greater, and 2 patients required subsequent MV reoperation. The 5-year survival, freedom from recurrent MR $(\geq 2+)$, and freedom from MV reoperation was $95.2 \%$ $\pm 2.8 \%, 92.6 \% \pm 3.9 \%$, and $94.0 \% \pm 4.9 \%$, respectively.
\end{abstract}

Conclusions: MV repair of bileaflet prolapse due to myxomatous disease is safe and durable. Successful repair often requires a combination of surgical repair techniques. (J Thorac Cardiovasc Surg 2012;143:S8-11)

Mitral valve (MV) repair is the preferred treatment of severe mitral regurgitation (MR) and is performed with increasing frequency compared with replacement. ${ }^{1}$ Successful repair of posterior leaflet prolapse has been well reported ${ }^{1,2}$; however, the long-term outcomes after repair of bileaflet prolapse are not as well described.

Several expert MV repair centers have reported favorable outcomes after MV repair of bileaflet prolapse. ${ }^{3-8}$ Freedom from MV reoperation in these patients has ranged from $93 \%$ at 2 years to $96 \%$ at 10 years. ${ }^{3,4} \mathrm{MV}$ repair in these studies have included minimally invasive approaches, chordal transfer, polytetrafluoroethylene neochords, and edge-to-edge repair. ${ }^{3-9}$ Most of these studies, however, have also included patients with mixed causes of MR, and

From the Division of Cardiac Surgery ${ }^{\mathrm{a}}$ and Department of Epidemiology and Community Medicine, ${ }^{\mathrm{b}}$ University of Ottawa, Ottawa, Ontario, Canada

Disclosures: Vincent Chan, Marc Ruel, Sophia Chaudry, Stephane Lambert, and Thierry G. Mesana have nothing to disclose with regard to commercial support.

Presented at The American Association for Thoracic Surgery Mitral Conclave, New York, New York, May 5-6, 2011.

Received for publication May 14, 2011; revisions received Dec 29, 2011; accepted for publication Jan 16, 2012; available ahead of print Feb 3, 2012.

Address for reprints: Thierry G. Mesana, MD, PhD, University of Ottawa Heart Institute, 3402-40 Ruskin Street, Ottawa, ON K1Y 4W7 Canada (E-mail: tmesana@ottawaheart.ca).

0022-5223/\$36.00

Copyright (c) 2012 by The American Association for Thoracic Surgery doi:10.1016/j.jtcvs.2012.01.046 few have addressed the outcomes in patients with myxomatous disease alone. ${ }^{4,6}$ Long-term assessments of recurrent MR in this population are also lacking.

We therefore performed a follow-up study involving 142 patients who had undergone MV repair of bileaflet prolapse due to myxomatous disease. The objective of the present study was to describe our surgical approach to bileaflet prolapse in these patients and to report our outcomes with regard to survival, recurrent MR $(\geq 2+)$, and MV reoperation.

\section{METHODS \\ Ethics Approval}

The University of Ottawa Heart Institute has existing ethics approval from its institutional research ethics board to anonymously publish data prospectively collected before and after heart valve surgery. As such, individual patient consent was waived.

\section{Patients}

From 2001 to 2010, 142 patients underwent MV repair of bileaflet prolapse due to myxomatous disease. These patients had typical myxoid degeneration and excess tissue involving both leaflets. All patients presented to the operating room with the intention to undergo MV repair. During this period, 7 patients with myxomatous disease and bileaflet prolapse (7 of 149, 95.3\% repair rate) underwent MV replacement. An additional 151 patients with myxomatous disease were also referred for MV repair during the study period, of whom 10 had isolated anterior leaflet 


\section{Abbreviations and Acronyms \\ $\mathrm{MR}=$ mitral regurgitation \\ $\mathrm{MV}=$ mitral valve}

prolapse and 141 had isolated posterior leaflet prolapse. Overall, 8 patients with myxomatous disease and prolapse, bileaflet or otherwise, required conversion to MV replacement (8 of $300,97.3 \%$ repair rate).

Patients with Barlow's disease had multiscallop prolapse and excess leaflet tissue, along with elongated or thickened chords on direct valve inspection. ${ }^{9}$ The excess tissue had to be present in at least 2 anterior leaflet scallops and 2 posterior leaflet scallops. All patients had severe mitral annular dilation and received a ring annuloplasty $36 \mathrm{~mm}$ or greater. Echocardiographically, bulky, billowing leaflets were also observed.

\section{Follow-up}

The patients were assessed regularly in a dedicated MV clinic. The patients were seen in the clinic 4 to 6 weeks after their initial surgery. Subsequent follow-up information was obtained annually either through direct clinic visits or telephone interviews. The clinic visits included a history and physical examination, electrocardiogram, chest radiograph, complete blood count, serum chemistries, and international normalized ratio (when applicable). Echocardiographic follow-up was also performed on all MV repair patients postoperatively at 1, 3 to 6, and 12 months postoperatively. After 1 year, echocardiograms were performed every 1 to 3 years or when clinically indicated. The mean follow-up was $3.0 \pm 2.1$ years (median, 2.7 ; maximum, 8.6). Valverelated complications were defined and recorded according to established criteria. ${ }^{10}$

\section{Operative Technique}

All MV repairs were performed with median sternotomy, cardiopulmonary bypass, and cardioplegic arrest with cold blood cardioplegia. $\mathrm{MV}$ annuloplasty was performed in all patients using the Medtronic $\mathrm{Fu}-$ tureband in 114 (Medtronic, Minneapolis, Minn), Duran Ancore Band in 22 (Medtronic), and the Carpentier-Edwards Physio Annuloplasty Ring in 6 (Baxter Healthcare, Irvine, Calif). Posterior leaflet prolapse was corrected with resection and sliding plasty in 96 patients $(68 \%)$ to prevent systolic anterior motion of the MV. The remaining 46 patients $(32 \%)$ received either a quadrangular or triangular resection without sliding plasty. Anterior leaflet correction included native chordal transfer in $73(51 \%)$ and the hybrid flip-over technique in 23 patients $(16 \%) .{ }^{11}$ In brief, the hybrid flip-over technique is used in the setting of bileaflet prolapse. If chordal transfer is not feasible after resection of the posterior leaflet, polytetrafluoroethylene neochordae are placed onto a remnant portion to the posterior leaflet close to the annulus, with subsequent transfer of the posterior leaflet tissue and neochordae to the anterior leaflet. This facilitates measurement of the artificial neochordae to the level of the MV annulus and provides a symmetric line of support to the anterior leaflet. ${ }^{11}$ The posterior leaflet is then reconstructed after the sliding plasty. Chordal transfer was the preferred approach to correct anterior leaflet prolapse in this population and was used if secondary chords to the posterior leaflet were not thin, elongated, or calcified. The presence of ruptured chordae did not necessarily preclude transfer of in situ chords. Isolated chordal replacement with polytetrafluoroethylene neochordae was performed in 15 patients and isolated edge-to-edge repair in 11 patients. Anterolateral commissuroplasty was performed in 5 and posteromedial commissuroplasty in 4 . A combination of polytetrafluoroethylene neochordae and an edge-to-edge repair was used in 5 patients. The median annuloplasty ring size was $32 \mathrm{~mm}$ (range, 26-38). In all patients who underwent MV repair, MR greater than 1+ or a mean mitral gradient greater than $5 \mathrm{~mm} \mathrm{Hg}$, determined intraoperatively, were indications for additional MV intervention. A concomitant maze procedure was performed for all patients with permanent atrial fibrillation or paroxysmal atrial fibrillation present for at least 6 months before surgery.

\section{Statistical Analysis}

The data were imported and analyzed in Stata, version 11.1 (StataCorp, College Station, Tex). Continuous variables are expressed as the mean \pm standard deviation and categorical variables are described as a percentage of the total. The Kaplan-Meier method was used to assess survival, freedom from recurrent $M R(\geq 2+)$, and freedom from MV reoperation.

\section{RESULTS}

\section{Baseline Characteristics}

The patient characteristics are listed in Table 1 . The average age of this cohort was $60.4 \pm 13.2$ years (range, 26-87), and $23 \%$ had atrial fibrillation preoperatively. The left atrial and left ventricle end-diastolic diameter was $48.8 \pm 8.1 \mathrm{~mm}$ and $58.2 \pm 7.7 \mathrm{~mm}$, respectively.

Barlow's disease was observed in 42 patients ( $30 \%$ ), and 76 patients $(54 \%)$ had prolapse of more than 2 anterior leaflet scallops. Prolapse of at least 4 scallops was observed in 83 patients $(58 \%)$ and prolapse of all 6 scallops in 18 $(13 \%)$. All patients had bileaflet chordal elongation. Rupture of the chords to the anterior leaflet occurred in 10 patients and rupture of chords to the posterior leaflet in 43 .

Concomitant coronary artery bypass grafting was performed in 16, aortic valve replacement in 1 , maze procedure in 20, and tricuspid valve repair in 15 . Four patients underwent MV repair by way of repeat sternotomy after previous coronary artery bypass grafting.

\section{Survival}

No intraoperative or hospital deaths occurred. Six late deaths occurred during follow-up from cerebrovascular accident in 1 , congestive heart failure in 2 , lower gastrointestinal bleeding in 1 , myocardial infarction in 1 , and unknown in 1 . The 5 -year survival was $95.2 \% \pm 2.8 \%$ (Figure 1 ).

\section{Freedom From Recurrent MR $(\geq 2+)$ and MV Reoperation}

Recurrent MR $(\geq 2+)$ was observed in 4 patients ( $3 \%)$ after repair, of whom 1 had more than $2+$ MR. Freedom from recurrent MR $(\geq 2+)$ was $97.5 \% \pm 1.7 \%$ at 1 year and $92.6 \% \pm$ $3.9 \%$ at 5 years (Figure 1). In patients whose repair involved native chordal transfer, the 5-year freedom from recurrent $\operatorname{MR}(\geq 2+)$ was $93.1 \% \pm 4.8 \%$. There were $2 \mathrm{MV}$ reoperations in the present series. One patient had recurrent 4+ MR 2.2 months after the initial repair due to failure of the polytetrafluoroethylene chordae to the anterior leaflet. These chordae were found to be torn on reoperation. He subsequently underwent mechanical MV replacement. The other patient developed severe mitral stenosis in addition to moderate MR secondary to pannus in-growth surrounding his full-ring annuloplasty. He underwent successful repeat repair of his MV 4.5 years after his initial operation. The 5-year freedom from MV reoperation was $94.0 \% \pm 4.9 \%$. 
TABLE 1. Patient, echocardiographic, and operative characteristics

\begin{tabular}{|c|c|}
\hline Characteristic & Value \\
\hline \multicolumn{2}{|l|}{ Patient characteristics } \\
\hline Age (y) & $60.4 \pm 13.2$ \\
\hline Atrial fibrillation* & $33(23)$ \\
\hline Diabetes mellitus & $2(1)$ \\
\hline Female gender & $36(25)$ \\
\hline NYHA class III-IV & $20(14)$ \\
\hline \multicolumn{2}{|l|}{ Preoperative echocardiographic characteristics } \\
\hline Left atrial diameter $(\mathrm{mm})$ & $48.8 \pm 8.1$ \\
\hline LV ejection fraction $\geq 50 \%$ & $120(85)$ \\
\hline LV end-diastolic diameter (mm) & $58.2 \pm 7.7$ \\
\hline LV end-systolic diameter (mm) & $35.6 \pm 8.4$ \\
\hline \multicolumn{2}{|l|}{ Preoperative RVSP class $\dagger$} \\
\hline I & $65(46)$ \\
\hline II & $44(31)$ \\
\hline III & $21(15)$ \\
\hline IV & $12(8)$ \\
\hline \multicolumn{2}{|l|}{ Mitral valve characteristics } \\
\hline Barlow’s disease $\ddagger$ & $42(30)$ \\
\hline Prolapse of $\geq 2$ anterior leaflet scallops & $76(54)$ \\
\hline Prolapse of $\geq 2$ posterior leaflet scallops & $103(73)$ \\
\hline \multicolumn{2}{|l|}{ Prolapsed scallops (n) } \\
\hline 4 & $51(36)$ \\
\hline 5 & $14(10)$ \\
\hline 6 & $18(13)$ \\
\hline \multicolumn{2}{|l|}{ Operative characteristics } \\
\hline Concomitant CABG & $16(11)$ \\
\hline Concomitant aortic valve replacement & $1(0.7)$ \\
\hline Concomitant maze procedure $\S$ & $20(14)$ \\
\hline Concomitant tricuspid valve repair & $15(11)$ \\
\hline Reoperative sternotomy & $4(3)$ \\
\hline
\end{tabular}

Data in parentheses are percentages. NYHA, New York Heart Association; $L V$, left ventricle; $C A B G$, coronary artery bypass grafting; $R V S P$, right ventricle systolic pressure. *Included permanent and known paroxysmal atrial fibrillation preoperatively. $\dagger$ RVSP class I, RVSP $<35 \mathrm{~mm} \mathrm{Hg}$; class II, RVSP $35-44 \mathrm{~mm} \mathrm{Hg}$; class III, RVSP 45-60 mm Hg; class IV, RVSP > $60 \mathrm{~mm} \mathrm{Hg.} \ddagger$ Patients with Barlow’s disease had multiscallop prolapse and excess leaflet tissue, along with elongated or thickened chords on direct valve inspection. Excess tissue required in $\geq 2$ anterior leaflet scallops and $\geq 2$ posterior leaflet scallops. All patients had severe mitral annular dilation and received a ring annuloplasty, size $\geq 36 \mathrm{~mm}$. Echocardiographically, bulky, billowing leaflets were also observed. §Included left-sided lesions only performed with Medtronic Cardioblate irrigated unipolar radiofrequency system (Medtronic, Minneapolis, Minn). A concomitant maze procedure was performed for all patients with permanent atrial fibrillation or paroxysmal atrial fibrillation present for $\geq 6$ months before surgery.

\section{Valve-Related Morbidity}

One fatal cerebrovascular accident and one fatal lower gastrointestinal bleeding episode, mentioned in the previous section, were observed during follow-up. No cases of endocarditis or additional cases of hemorrhage or thromboembolism were observed. The 5-year freedom from hemorrhage and thromboembolism was $98.9 \% \pm 1.1 \%$ and $98.3 \% \pm 1.7 \%$, respectively.

\section{DISCUSSION}

In the present study, we described our experience with MV repair of bileaflet prolapse due to myxomatous disease.

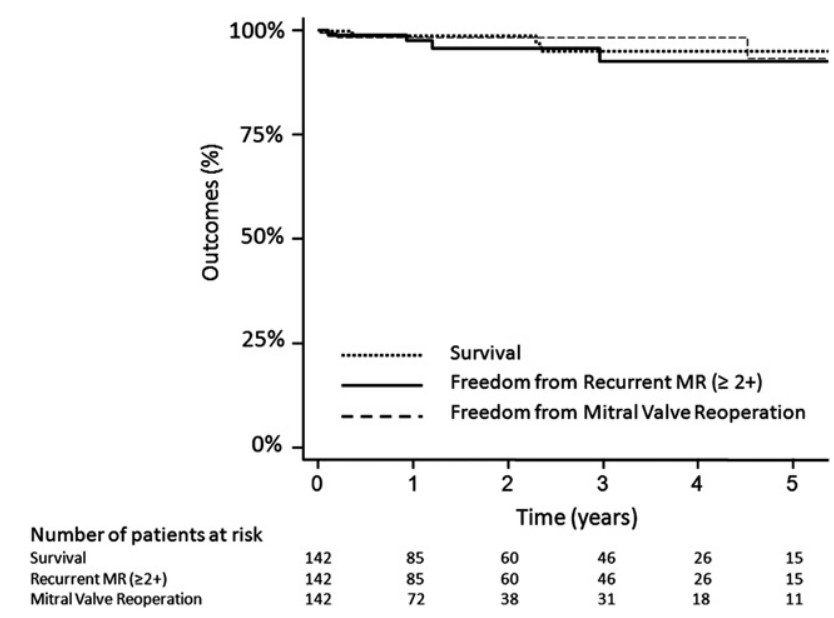

FIGURE 1. Outcomes after mitral valve repair of myxomatous bileaflet prolapse. Overall survival, freedom from recurrent $M R(\geq 2+)$, and freedom from mitral valve reoperation shown. At follow-up, 6 patients died, 4 patients had recurrent $M R(\geq 2+)$, and 2 patients underwent mitral valve reoperation. The mean clinical follow-up interval was $3.0 \pm 2.1$ years, and the mean echocardiographic follow-up interval was $2.6 \pm 2.1$ years.

The demographics of the patients in the present study were similar to others describing MV repair of myxomatous disease. Published series have involved cohorts aged 40 to 60 years. ${ }^{4,6}$ Similar to our series, others also had one third of patients with preoperative atrial fibrillation, and approximately $15 \%$ required concomitant coronary artery bypass grafting. ${ }^{4,6}$ Patients with Barlow's disease typically present with multiscallop prolapse, ${ }^{4,6,9}$ and in the present study, one half had prolapse of more than 2 anterior leaflet scallops and three quarters had prolapse of more than 2 posterior leaflet scallops. Experienced centers have also reported $0 \% 30$-day mortality. ${ }^{4,6}$

Our approach to MV repair in patients with bileaflet prolapse and myxomatous disease involves a combination of surgical techniques. Anyanwu and Adams ${ }^{9}$ emphasized the importance of appropriate annuloplasty sizing. Although several annuloplasty systems were used in the present study, the C-shaped, semirigid, Medtronic Futureband (Medtronic) has been exclusively used at our institution since 2004. Our preferred repair technique in patients with bileaflet prolapse is chordal transfer with associated posterior leaflet plication. The 5-year freedom from recurrent MR $(\geq 2+)$ was $93 \%$ for patients who received chordal transfer as a part of the MV repair. To our knowledge, no series have described the long-term outcomes after chordal transfer in patients with bileaflet prolapse.

However, native chordae that are not thin, elongated, or calcified might not be available. In these instances, we use polytetrafluoroethylene chords or an edge-to-edge repair. David and colleagues ${ }^{4}$ reported $96 \%$ freedom from MV reoperation in patients using primarily polytetrafluoroethylene neochordae. Others have also reported favorable early results with artificial neochords. ${ }^{3,5,8}$ In the present study, the 1 patient who 
developed recurrent 4+ MR and required MV reoperation developed failure of polytetrafluoroethylene chordae to the anterior leaflet. These chords were found to be torn on reoperation. However, the results from the present series also suggest favorable durability with artificial chordae. The edge-to-edge repair was used primarily in older patients with isolated A2-P2 prolapse and associated annular calcification.

In patients with extensive anterior leaflet prolapse without adequate native chords, we used the hybrid flip-over technique. ${ }^{11}$ This involves placement of polytetrafluoroethylene neochordae to a portion of the posterior leaflet, which is then transferred to the anterior leaflet. This facilitates measurement of neochordae to the height of the MV annulus, while providing a broad area of support to the anterior leaflet. ${ }^{11}$ In the present series, the hybrid flip-over technique was used in $16 \%$ of the patients.

Valve-related complications were rarely observed during study follow-up. ${ }^{10}$ These data therefore emphasize the clinical benefits of MV repair over replacement.

\section{Study Limitations}

These data constitute a single-center experience with midterm follow-up. The risk factors associated with survival, recurrent MR, and MV reoperation were not determined owing to the low number of events.

\section{CONCLUSIONS}

MV repair of bileaflet prolapse due to myxomatous disease is safe and durable. Successful repair often requires a combination of surgical repair techniques.

\section{References}

1. Gammie JS, Zhao Y, Peterson ED, O'Brien SM, Rankin JS, Griffith BP. Less-invasive mitral valve operations: trends and outcomes from the Society of Thoracic Surgeons Adult Cardiac Surgery Database. Ann Thorac Surg. 2010;90:1401-10. 1410.e1.

2. Grisoli D, Chan V, Tran A, Ressler L, Nicholson D, Hynes M, et al. Frequency and surgical management of complex posterior leaflet prolapse of the mitral valve. J Heart Valve Dis. 2010;19:568-75.

3. Duebener LF, Wendler O, Nikoloudakis $\mathrm{N}$, Georg $\mathrm{T}$, Fries $\mathrm{R}$, Schäfers HJ. Mitral-valve repair without annuloplasty rings: results after repair of anterior leaflet versus posterior-leaflet defects using polytetrafluoroethylene sutures for chordal replacement. Eur J Cardiothorac Surg. 2000;17: 206-12.

4. David TE, Omran A, Armstrong S, Sun Zhao, Ivanov J. Long-term results of mitral valve repair for myxomatous disease with and without chordal replacement with expanded polytetrafluoroethylene sutures. J Thorac Cardiovasc Surg. 1998; 115:1279-86.

5. Rodriguez E, Nifong LW, Chu MW, Wood W, Vos PW, Chitwood WR. Robotic mitral valve repair for anterior leaflet and bileaflet prolapse. Ann Thorac Surg. 2008;85:438-44.

6. Lapenna E, Torracca L, De Bonis M, La Canna G, Crescenzi G, Alfieri O. Minimally invasive mitral valve repair in the context of Barlow's disease. Ann Thorac Surg. 2005;79:1496-9.

7. McClure RS, Cohn LH, Wiegerinck E, Couper GS, Aranki SF, Bolman RM III, et al. Early and late outcomes in minimally invasive mitral valve repair: an eleven-year experience in 707 patients. J Thorac Cardiovasc Surg. 2009;137: $70-5$.

8. Seeburger J, Borger MA, Doll N, Walther T, Passage J, Falk V, et al. Comparison of outcomes of minimally invasive mitral valve surgery for posterior, anterior and bileaflet prolapse. Eur J Cardiothorac Surg. 2009;36:532-8

9. Anyanwu AC, Adams DH. Bileaflet repair for Barlow syndrome. Semin Thorac Cardiovasc Surg. 2010;22:179-83.

10. Akins CW, Miller DC, Turina MI, Kouchoukos NT, Blackstone EH, Grunkemeier GL, et al. Guidelines for reporting mortality and morbidity after cardiac valve interventions. J Thorac Cardiovasc Surg. 2008;135: 732-8.

11. Mesana TG, Ibrahim M, Kulik A, Ruel M, Dover K, Nicholson D, et al. The "hybrid flip-over" technique for anterior leaflet prolapse repair. Ann Thorac Surg. 2007;83:322-3. 